\title{
Letter
}

\section{Tissue Doppler in critical illness}

\section{Michelle Chew ${ }^{1}$, Lill Bergenzaun ${ }^{1}$, Anders Ersson ${ }^{1}$ and Hans Öhlin ${ }^{2}$}

\author{
1Department of Intensive Care Medicine, Entrance 42 Level 2, Malmö University Hospital, S-20502 Malmö, Sweden \\ 2Department of Cardiology, Lund University Hospital, 22185 Lund, Sweden
}

Corresponding author: Michelle Chew, michelle.chew@med.lu.se

Published: 4 December 2007

Critical Care 2007, 11:424 (doi:10.1186/cc6178)

This article is online at http://ccforum.com/content/11/6/424

(c) 2007 BioMed Central Ltd

See related research by Sturgess et al., http://ccforum.com/content/11/5/R97

We applaud Sturgess and colleagues [1] for their report on tissue Doppler imaging (TDI) in critical illness. Although their patients were selected and transthoracic echocardiography was performed at variable times after intensive care unit admission, the results provide a glimpse into the use of TDI and have generated many hypotheses. Indeed, there is a paucity of data regarding TDI in the critically ill patient, and further studies evaluating echocardiographic parameters in this population are urgently needed.

Our unit is currently conducting a cohort study in patients with severe sepsis/systemic inflammatory response syndrome receiving daily transthoracic echocardiography for 7 days or until intensive care unit discharge. While our study has not been fully completed, we have also found that impaired relaxation is common, with a peak early diastolic mitral annular velocity $<9.6 \mathrm{~cm} / \mathrm{s}$ in $54 \%$ of patients on day 1 . This patient proportion decreases to $13 \%$ on day 7 . Elevated filling pressures (peak early diastolic transmitral velocity/peak early diastolic mitral annular velocity ratio $>15$ ) were found in $17 \%$ of patients on day 1 and persisted in $13 \%$ of patients on day 7 , findings similar to those reported by Sturgess and colleagues [1]. TDI can also be used to assess systolic function, and is a useful adjunct to more traditional measurements such as the ejection fraction.

The implications of TDI parameters for clinical outcome will be relevant investigations for the future. Our experience is that TDI measurements are relatively easy to obtain even in ventilated patients. Furthermore, as Sturgess and colleagues allude, the peak early diastolic mitral annular velocity may be a reasonably robust indicator of diastolic function. We urge intensivists to use TDI, and to specifically evaluate diastolic function when conducting echocardiographic examinations in the intensive care unit.

\section{Competing interests}

The authors declare that they have no competing interests.

\section{Reference}

1. Sturgess DJ, Marwick TH, Joyce CJ, Jones M, Venkatesh B: Tissue Doppler in critical illness: a retrospective cohort study. Crit Care 2007, 11:R97.

TDI = tissue Doppler imaging 